\title{
OS IMPASSES SOCIOAMBIENTAIS ORIUNDOS DA MINERAÇÃO NA COLÔMBIA: UM OLHAR DIANTE DO DESENVOLVIMENTO SUSTENTÁVEL E DO ESTADO DE DIREITO AMBIENTAL ${ }^{1}$
}

\section{THE SOCIO-ENVIRONMENTAL IMPASSES ARISING FROM MINING IN COLOMBIA; A VIEW ON SUSTAINABLE DEVELOPMENT AND THE STATE OF ENVIRONMENTAL LAW}

\author{
Ariel Sousa Santos* \\ Rayza Ribeiro Oliveira**
}

\begin{abstract}
Resumo: A prática da mineração é uma realidade em muitos países do globo, especialmente na Colômbia. Muitos indivíduos dependem desta atividade extrativista para sua subsistência. Contudo, a sua prática indiscriminada, ilegal e informal causa diversos problemas ao meio ambiente e à população local. Assim, justifica-se este trabalho em razão do seu caráter socioambiental, que necessita da atenção do governo e do meio acadêmico. Com isso, esta pesquisa tem como objetivo geral analisar as problemáticas ocasionadas pela mineração na Colômbia. Para isto, a construção deste artigo dar-se-á por meio de técnicas de pesquisa bibliográfica de natureza básica, do tipo descritiva-explicativa. Quanto ao procedimento técnico, a pesquisa será de estudo de caso. Destarte, contatou-se que a Colômbia apresenta uma legislação que regula a mineração, mas que não é cumprida em sua totalidade. Portanto, a aplicação do Desenvolvimento Sustentável, tendo como pilar o Estado de Direito Ambiental, efetivará o já disposto em lei.
\end{abstract}

Palavras-chave: Colômbia. Desenvolvimento Sustentável. Estado de Direito Ambiental. Mineração.

Abstract: The practice of mining is a reality in many countries around the globe, especially in Colombia. Many individuals depend on this extractive activity for their subsistence. However, its indiscriminate, illegal and informal practice causes several

\footnotetext{
${ }^{1}$ Este artigo inédito é fruto parcial dos resultados do projeto de pesquisa de iniciação científica "Acidentes com barragens de rejeitos de mineração e responsabilidade no ordenamento jurídico brasileiro: uma correlação com os principais casos do Peru, Chile e Colômbia no período 2010-2019" desenvolvido por integrantes do Grupo de Estudos em Direitos Humanos, Ambiente e Sustentabilidade (GEDHAS) e do Grupo de Pesquisa Direitos Fundamentais, Novos Direitos e Evolução Social com registro no CNPq.

* Graduando em Direito pela Universidade Tiradentes (UNIT). Voluntário no Programa Voluntário de Iniciação Científica (PROVIC). Bolsista no Programa de Bolsa de Iniciação Científica (PROBIC). Membro do Grupo de Estudos em Direitos Humanos, Ambiente e Sustentabilidade (GEDHAS). E-mail: arielss187@gmail.com.

** Mestrado em Direitos Humanos pela Universidade Tiradentes (UNIT). Especialista em Direito Urbanístico e Ambiental pela Pontifícia Universidade Católica de Minas Gerais (PUC/MG). Graduada em Direito pela Universidade Tiradentes (UNIT). Docente de Direito Civil e Processual Civil, Prática Cível, IED e Ciência Política no Centro Universitário Estácio de Sergipe. Coordenadora do Grupo de Estudos em Direitos Humanos, Ambiente e Sustentabilidade (GEDHAS). Integrante do Grupo de Pesquisa Direitos Fundamentais, Novos Direitos e Evolução Social com registro no CNPq. E-mail: rayzaribeiro.oliveira@gmail.com.
} 
problems to the environment and to the local population. Thus, this work is justified due to its socio-environmental character, which needs the attention of the government and of the academic environment. Therefore, this research has as general objective to analyze the problems caused by mining in Colombia. For this, the construction of this article will take place by means of bibliographic research techniques of a basic nature, in a descriptive-explanatory type, by the inductive method. As for the technical procedure, the research will be a case study. Thus, it was found that Colombia has a legislation that regulates mining, but that is not fully complied with. Therefore, the application of Sustainable Development, based on the State of Environmental Law, will give effect to the provisions of the law.

Keywords: Mining. Colombia. Sustainable Development. State of Environmental Law. 


\section{INTRODUÇÃO}

A prática das atividades de mineração é uma realidade marcante na América Latina, especialmente na Colômbia. Neste país, o exercício da mineração acarreta inúmeros entraves socioambientais, tendo em vista que a maior parte da mineração do país é informal e ilegal.

Assim, a realização desta atividade extrativista prejudica seriamente tanto o meio ambiente quanto a população local, levando em consideração que esta depende diretamente dos recursos naturais para sua subsistência.

Ademais, cabe frisar que diante da degradação de um ecossistema, torna-se difícil, ou até mesmo impossível, a sua reparação. Com isso, destaca-se que a Colômbia apresenta normas legais que regulam e fiscalizam a prática da mineração neste país, a exemplo da Resolução 40391 de 2016 que adotam a Política Nacional de Mineração. No entanto, estes dispositivos não são cumpridos e efetivados em sua totalidade, ocasionando, assim, entraves socioambientais.

Dessa forma, tem-se a aplicação e a efetivação do Desenvolvimento Sustentável, que tem como pilar o Estado de Direito Ambiental, como mecanismos que atenuam as consequências oriundas das atividades de mineração.

Diante disso, a escolha deste tema deu-se em razão dos inúmeros questionamentos e lacunas que o permeiam. Caracterizando-se como uma problemática de caráter socioambiental que necessita da atenção não só do governo, como também do meio acadêmico.

Com isso, questiona-se: Como se dá o cumprimento da legislação colombiana que regula a mineração, e, consequentemente, a preservação do meio ambiente? E como o Desenvolvimento Sustentável e o Estado de Direito Ambiental podem amenizar as consequências desta atividade extrativista?

Deste modo, o presente artigo tem como objetivo geral analisar, sem pretensão de esgotar outros enfoques de análise total acerca do tema, a mineração na Colômbia diante da efetivação da sua legislação ambiental. No que diz respeito aos objetivos específicos, estes dividir-se-ão em três tópicos: apresentar o direito dos desastres e o direito ambiental em face da mineração colombiana, averiguar a legislação da Colômbia diante dos impasses socioambientais oriundos das atividades 
de mineração e mostrar o Desenvolvimento Sustentável e o Estado de Direito ambiental como mecanismos que atenuam as consequências da mineração.

No que concerne à Metodologia Científica, a construção deste artigo dar-se-á por meio de técnicas de pesquisa bibliográfica (desenvolvida a partir de material já publicado), de natureza básica (responder-se-á às perguntas para ampliar conhecimentos) e do tipo descritiva-explicativa.

Destarte, quanto ao procedimento técnico, a pesquisa será de estudo de caso, ou seja, haverá um estudo profundo, detalhado e exaustivo dos objetos de estudo, possibilitando-se o seu amplo conhecimento.

\section{DIREITO DOS DESASTRES E O DIREITO AMBIENTAL EM FACE DA MINERAÇÃO LATINO-AMERICANA}

A mineração é uma atividade extrativista predominante em diversos países do globo. No entanto, esta prática acarreta implicações socioambientais. Desde o final dos anos 1990, com a expansão da globalização e com o aumento do consumo de metais, os conflitos territoriais relacionados à mega mineração a céu aberto no continente latino-americano intensificaram-se. Ademais, a indústria mineral tem crescido em um ritmo acelerado, tanto em volumes extraídos, quanto pela abertura de novas minas, que, em geral, são autorizadas apenas pelo poder central, excluindo-se os moradores locais. (SCOTTO, 2011).

A estratégia empresarial dos grandes grupos multinacionais dá-se, em escala global, através da concentração de projetos extrativos na América do Sul e na periferia em geral. O fluxo dominante é do Sul para o Norte; os metais e materiais têm origem, principalmente, na América Latina e na África e seu destino são os Estados Unidos, o Canadá, a União Europeia e a China. (ARAUJO; FERNANDES, 2016, p. 65-66).

À vista disso, destaca-se que a exploração de minérios na América Latina, especialmente na Colômbia, acarreta problemáticas socioambientais. Ou seja, o exercício desta atividade acarreta prejuízos tanto ao meio ambiente, quanto à população local.

Neste sentido, empregou-se ao longo desta pesquisa o termo "desastre ambiental" como forma de classificar os danos decorrentes da atividade de 
mineração. Além disso, é imprescindível mencionar que há um nexo de ligação entre o Direito Ambiental e o Direito dos Desastres.

Assim, salienta-se que os déficits na regulação ambiental potencializam o surgimento de desastres (FARBER, 2011, p. 1802), tais como ocupação irregular do solo, contaminações em larga escala, desrespeito à proteção de áreas de preservação permanente, ausência de reservas legais, ocupação irregular de áreas em encostas de morros e de áreas propensas a inundações. Com isso, nota-se que o Direito Ambiental está interligado umbilicalmente ao Direito dos Desastres. (CARVALHO, 2020, p. 36).

Além disso, os desastres dizem respeito a eventos que atingem comunidades. Assim, estes fenômenos apresentam uma relevância jurídica, como desastres, quando atingem uma dimensão social (SUGARMAN, 2007, p. 3). Ademais, são decorrentes de fenômenos humanos, naturais ou mistos (conjunta ou isoladamente), desencadeados lentamente ou de forma temporalmente instantânea (CARVALHO, 2020, p. 36). Em outras palavras, os desastres são descritos como eventos que superam a capacidade local ou regional em prestar resposta ao evento. (FARBER, 2011, p. 1785).

Por fim, para complementar sua definição, os desastres consistem em eventos (de causa natural, humana ou mista) capazes de comprometimento de funções ambientais ou lesão a interesses humanos decorrentes de alguma mudança ambiental. Este é o ponto de interseç̧ão entre o Direito Ambiental e o Direito dos Desastres. (CARVALHO, 2020, p. 38).

Diante do exposto, notou-se a forte presença da mineração na América Latina. Além disso, para uma melhor compreensão desta problemática em análise, delimitou-se a classificação das consequências desta atividade como sendo "desastres ambientais".

Outrossim, vislumbrou-se que o Direito Ambiental está interligado ao Direito dos Desastres. Neste viés, no capítulo seguinte será analisada a legislação da Colômbia que regula as atividades de mineração, bem como as consequências negativas oriundas da mineração. 


\section{A LEGISLAÇÃO COLOMBIANA EM FACE DOS IMPASSES SOCIOAMBIENTAIS ORIUNDOS DAS ATIVIDADES DE MINERAÇÃO}

Diante da explanação do capítulo anterior, a respeito da mineração na América Latina e da ligação entre o Direito dos Desastres e o Direito Ambiental, neste momento, faz-se necessário delimitar a área de abrangência desta pesquisa, que será voltada para análise dos impasses sociais e ambientais que ocorrem na Colômbia em razão da mineração.

Contudo, primeiramente, importante analisar a legislação colombiana referente à regulação das atividades de mineração. Para isso foi analisada a Resolução 40391 de 2016 que adota a Política Nacional de Mineração. (COLÔMBIA, 2016).

Este documento é constituído com a estrutura operacional e a linha estratégica para o desenvolvimento do setor minerário no país. Nele, é possível encontrar uma análise contextual dos principais desafios do setor, bem como a estrutura estratégica e os pilares que devem ser levados em consideração para que a atividade gere valor agregado ao desenvolvimento das regiões, por meio de diálogo e instrumentos tripartidos de boas práticas. (VILLALOBOS, 2016).

O documento declara que a mineração na Colômbia possui alguns desafios, como altos níveis de informalidade, a extração ilegal de minerais, as decisões judiciais que geram instabilidade legal, conflitos sociais e ambientais, dentre outros. Com isso, essa resolução busca contribuir para a extração de minerais sob parâmetros técnicos, ambientais, econômicos, trabalhistas e sociais adequados. Visando, com isso, melhorias na qualidade de vida da população e preservação do meio ambiente. (VILLALOBOS, 2016).

Essa nova política de mineração terá como pilares basilares: segurança jurídica, condições competitivas, confiança legítima, infraestrutura, informações e autoridade de mineração fortalecida e eficiente. (VILLALOBOS, 2016).

Além disso, o documento refere-se à administração do recurso de mineração na Colômbia, incluindo as atividades de contratação e titulação, bem como a inspeção de mineração. (VILLALOBOS, 2016).

O controle da mineração é realizado por meio de avaliação ambiental e inspeções de campo. A avaliação documental consiste em avaliar o cumprimento de 
todas as obrigações legais e contratuais. Já as inspeções de campo referem-se à parte da inspeção que verifica o cumprimento das obrigações derivadas do título de mineração e dos regulamentos atuais. (VILLALOBOS, 2016).

Diante do exposto, nota-se que a Colômbia possui uma legislação que regula as atividades de mineração neste país. Assim, a Resolução 40391 de 2016, que adota a Política Nacional de Mineração, contribui para a formalização da mineração, para que assim os impactos desta atividade não prejudiquem tanto o meio ambiente e a população local.

Contudo, destaca-se que as normas legais que regulam as atividades de mineração na Colômbia não são cumpridas e efetivadas em sua totalidade, acarretando, assim, em problemas ambientais e sociais, que serão explanados no subtópico seguinte.

\subsection{As problemáticas socioambientais ocasionadas pela mineração na Colômbia}

Finda a explanação acerca da legislação minerária colombiana, neste momento, urge-se mostrar que o dispositivo legal supracitado não é cumprido em sua totalidade, tendo em vista que é possível visualizar que inúmeros problemas acarretam danos ao meio ambiente e à população.

A mineração na Colômbia encontra-se pulsante desde o período précolombiano. A partir do século XX, a extração minerária se estendeu por quase todo o território nacional, sendo caracterizada por sua heterogeneidade, tanto no uso de técnicas de extração quanto na grande diversidade de materiais obtidos. Antes mesmo que o ouro colombiano fosse alvejado pelos conquistadores, este mineral já era um meio de subsistência para grande parte da população. (QUIJANO; PARDO, 2010).

Neste sentido, frisa-se que a mineração é uma das atividades extrativistas mais praticadas em todo o mundo. Tendo em vista que muitos países dependem economicamente da sua realização. Contudo, o seu exercício, indiscriminado ilegal, acarreta problemáticas de caráter social e ambiental.

Com isso, a mineração é um estágio para o desenvolvimento dos países (DAVIS, 1998). Entretanto, a atividade de mineração implica destruição da vegetação 
ou impedimento de sua recuperação. Em muitas situações, o solo é removido ficando exposto aos processos erosivos, que podem acarretar assoreamento dos corpos d'água dos entornos. (RADETZKI, 1982).

Em meados dos anos 2000, somente 0,98\% da Colômbia encontrava-se titulada em todo o seu território para fins de exploração minerária. Hoje a área alcança $36 \%$ do território colombiano. (SIMCO, 2014).

Além disso, de acordo com os dados do Cadastro Mineiro, até 2012 por volta de $6,02 \%$ dos territórios afro colombianos contavam com títulos de mineração e $16,50 \%$ encontravam-se sob solicitação junto da Autoridade Nacional de Licenças Ambientais (ANLA, 2015) para o desenvolvimento de atividades de mineração. (SIMCO, 2014).

Diante disso, nota-se que a realização da atividade de mineração é prática presente na Colômbia. Sendo assim, é primordial sua análise, para que assim seja possível identificar as suas consequências socioambientais.

Neste sentido, convém analisar as consequências advindas das atividades de mineração na Colômbia. Para isto, foram investigadas algumas regiões da Colômbia, dentre elas, o Departamento de Antioquia (Bajo Cauca), Departamento De Cauca, Departamento del Chocó, Departamento de Córdoba, Departamento Bolívar e o Departamento de Caldas.

De acordo com o Relatório Temático Sobre Saúde da Secretaria Seccional de Saúde e Proteção Social de Antioquia, nesta região existem 1.600 minas informais. No Nordeste, 244 minas formais e 796 minas informais; no Bajo Cauca são identificadas 466 minais informais e 186 formais; no Sudoeste, existem 212 formais e 123 informais; no Oeste, 165 formais e 82 informais; e em Magdalena Medio, 133 formais e 30 informais. Por fim, existem 445 pedidos de legalização. (GÓMEZ et al., 2015, p. 24).

Outrossim, a mineração ilegal causa inúmeros danos ao meio ambiente nesta região. É possível ver a turbidez da água de rios como o Nechí devido aos resíduos da remoção de materiais. Na fase de recuperação do mineral, são utilizados cianeto e mercúrio, elementos que poluem o ar, devido aos gases que emanam. Além disso, ao remover grandes quantidades do solo, sua qualidade é alterada e afeta a capacidade de apoiar a atividade biológica, e também está contaminado com 
produtos químicos, como combustíveis, lubrificantes e a disposição de resíduos, estéreis e detritos. (GÓMEZ et al., 2015, p. 34).

No que concerne ao Departamento Del Cauca, a atividade de mineração aurífera é $80 \%$ ilegal nesta região. Métodos de exploração como uso de retroescavadeiras, dragas e bombas de motor causam impactos nessa área. Com isso, as fontes de água nas cidades de Mindalá e La Toma no município de Suárez possuem uma grande quantidade de sedimentos causados pela remoção de solo e subsolo e manejo inadequado de resíduos, estéreis e detritos. (GÓMEZ et al., 2015, p. 47).

Ademais, substâncias químicas e industriais utilizadas nos processos de obtenção do metal são descarregadas no reservatório de La Salvajina, alterando as características físico-químicas do recurso. (GÓMEZ et al., 2015, p. 24).

Outro problema que chama atenção nesta região é que grandes quantidades do solo são removidas, causando a perda de sua estrutura e afetando a função de apoio à atividade biológica e à regulação da água, e são despejadas nele substâncias químicas, combustíveis e lubrificantes, bem como são dispostos inadequadamente resíduos, estéreis e detritos. Como se não bastasse, estéreis e detritos são dispostos a céu aberto, e, com a ação do vento, causam um aumento na quantidade de partículas no ar. (GÓMEZ et al., 2015, p. 24).

Partindo para investigação do Departamento Del Chocó, de acordo com o censo de mineração disponibilizado pelo governo colombiano e as visitas de controle e acompanhamento realizadas em 2012 em 14 municípios do departamento, estavam em operação 260 instalações ilegais de mineração. (GÓMEZ et al., 2015, p. $60)$.

Além disso, na região supracitada, a mineração ilegal do ouro acarreta problemas na água pela sedimentação e contaminação. Já o solo é danificado pela extração indiscriminada de madeira das florestas tropicais úmidas, o que gera a mudança natural dos leitos dos rios. Ainda há emissões atmosféricas do processo de extração de ouro, prata e outros, devido às altas temperaturas geradas, como resultado do processo. (GÓMEZ et al., 2015, p. 63-68).

No que concerne ao Departamento de Córdoba, são explorados minerais como o carvão, níquel e ouro. Este último feito de duas maneiras: inundação e veia, 
ambas sem as permissões exigidas por lei. Essa atividade causa danos nas águas, como alterações de suas condições naturais pela liberação de resíduos sólidos e esgotos e entupimento por lama, acumulação de sedimentos e de eutrofização, contaminação com matéria orgânica que favorece a proliferação na superfície das plantas aquáticas. (GÓMEZ et al., 2015, p. 70-89).

Nesta área, a mineração ilegal, principalmente a realizada com dragas e retroescavadeiras, está levando à erosão das bacias hidrográficas em razão da destruição da flora. Além disso, os processos de mineração do ouro usam mercúrio para a separação final do ouro, que é feita ao ar livre e sem nenhum cuidado com o meio ambiente. (GÓMEZ et al., 2015, p. 70-89).

No que diz respeito aos municípios do Departamento de Bolívar, o governo nacional concedeu 240 títulos de mineração de ouro e outros minerais associados, 57 na fase de exploração, 111 na fase de construção e montagem e 45 em operação. Dos títulos concedidos e em vigor, nenhum se sobrepõe a áreas estratégicas de mineração em Bolívar. Todavia, algumas se sobrepõem às áreas de proteção e desenvolvimento de recursos naturais renováveis ou ao meio ambiente. (GÓMEZ et al., 2015, p. 90-110).

A pressão exercida nos últimos anos pela força pública contra a mineração criminal gerou a necessidade de os mineiros formalizarem suas atividades, fazendo surgir 209 pedidos de legalização desde 2001. Na região do Departamento de Bolívar, embora os municípios próximos estejam enriquecendo sua economia, a atividade de mineração é realizada sem as devidas autorizações, gerando sérios impactos ao meio ambiente, como poluição das águas, desmatamentos desenfreados e poluição atmosférica. (GÓMEZ et al., 2015, p. 90-110).

Por fim, em relação ao Departamento de Caldas, no município de Riosucio, a atividade de mineração é realizada principalmente pela comunidade indígena, que cumpre os regulamentos de mineração. A atividade extrativista é realizada de maneira setorizada e controlada, não há remoção visível da cobertura vegetal porque a atividade de mineração é realizada no subsolo. (GÓMEZ et al., 2015, p. 133).

Além disso, os membros da comunidade reflorestam as bacias com espécies nativas como condição para exercer a exploração. Entretanto, um problema que aflige este município é o desmatamento das bacias na parte superior com finalidades 
comerciais para a atividade de mineração, que altera os fluxos das principais fontes de água que abastecem os aquedutos e afeta principalmente a população residente. (GÓMEZ et al., 2015, p. 133).

Diante do exposto, com a análise do Departamento de Antioquia (Bajo Cauca), Departamento De Cauca, Departamento del Chocó, Departamento de Córdoba, Departamento Bolívar e do Departamento de Caldas, vislumbrou-se que estas são regiões que vêm sofrendo impactos socioambientais em decorrência das atividades de mineração.

Diante do exposto, conclui-se que a Colômbia, apesar de apresentar uma legislação que protege o meio ambiente e todos os direitos inerentes a ele, ainda assim apresenta-se falhas. Uma vez que as regiões supracitadas sofrem impactos socioambientais ocasionados pela mineração, tendo em vista que esta atividade está sendo realizada de forma ilegal e informal.

\section{O DESENVOLVIMENTO SUSTENTÁVEL E O ESTADO DE DIREITO AMBIENTAL COMO MECANISMOS DE PROTEÇÃO SOCIOAMBIENTAL}

Diante dos entraves socioambientais ocasionados pela mineração, apresentam-se o Desenvolvimento Sustentável e o Estado de Direito Ambiental como dispositivos que protegem o meio ambiente e asseguram à população todos os direitos e garantias inerentes a ele.

Ao tratar da questão ambiental, os problemas ambientais da modernidade podem ser classificados em dois grupos: os de primeira geração, caracterizados pela linearidade dos impactos produzidos, e os de segunda geração, particularizados pela produção de efeitos complexos e intrincados. (CANOTILHO; LEITE, 2008).

Os problemas ambientais de primeira geração, embora constituam pressuposto para a caracterização de normas de controle antropicamente centrados, não estão restritos a um determinado período ou a uma conjuntura específica. Ou seja, os problemas ambientais, sejam eles de primeira ou de segunda geração, coexistem, exigindo que o sistema jurídico esteja sempre em busca de mecanismos de compatibilização. Já os problemas ambientais de segunda geração são oriundos de fontes de poluição dispersas e capazes de produzir impactos globais, transfronteriços e ilimitados em função do tempo. (CANOTILHO; LEITE, 2008). 
Em razão destes problemas ambientais, haverá uma intervenção na qualidade de vida de sucessivas gerações. Com isso, evidencia-se que as decisões tomadas no presente estão umbilicalmente interligadas com o futuro (LEITE; BELCHIOR, 2010, p. 298). Assim, se as gerações atuais continuarem a utilizar o meio ambiente sem a adoção de medidas restritivas, comprometerão os interesses ambientais das gerações vindouras. (CANOTILHO; LEITE, 2008).

Em vista disso, é importante destacar que, hodiernamente, há uma preocupação maior com as problemáticas ambientais, que estão associadas à evolução do homem, da ciência e da tecnologia (RUSCHEL, 2007, p. 24). Por essa razão, é fundamental apresentar mecanismos que atenuam as consequências advindas das atividades humanas que degradam o meio ambiente.

Com isso, tem-se o Estado de Direito Ambiental, que traz o Meio Ambiente como o maior valor a ser considerado. Por esta razão, o Direito assume uma concepção diferenciada da clássica noção antropocêntrica, para uma concepção biocêntrica ou ecocêntrica. (RUSCHEL, 2007, p. 56).

Contudo, antes de analisar o conceito de Estado de Direito Ambiental, é necessário compreender a definição de Desenvolvimento Sustentável, tendo em vista que são termos interligados e dependentes um do outro.

Durante o Prêmio Nobel de Economia de 1998, Amartya Sen definiu o desenvolvimento como um processo contínuo que leva à implementação de liberdades substantivas, que ele chama de "entitulamentos" (entitlement) econômicos, garantia de transparência, segurança protetora e oportunidades sociais (COSTA, 2003, p. 153). Atrela-se a esta concepção de desenvolvimento o conceito de "desenvolvimento sustentável".

Ao defender um desenvolvimento que "atenda às necessidades da geração atual sem comprometer as necessidades das gerações futuras", o relatório Brundtland destacava a necessidade de satisfazer simultaneamente os imperativos do desenvolvimento e do meio ambiente. (COSTA, 2003, p. 154).

Com isso, depreende-se que a Sustentabilidade deve ser "construída socialmente", ou seja, buscar acordos de natureza social, econômica e ecológica, além de propiciar um conjunto de técnicas sociais capazes de induzir à ação social coordenada e ajudar no desenvolvimento de capital social, criando grupos e 
associações no sentido de priorizar as pessoas e conceber estratégias envolvendo os atores sociais. (COSTA, 2003, p. 154).

Assim, a Sustentabilidade é um princípio constitucional que determina a responsabilidade não só do Estado, mas também da sociedade, para a concretização do desenvolvimento material e imaterial socialmente incluso, durável, equânime, ambientalmente limpo, inovador, ético e eficiente. (FREITAS, 2011).

Ademais, criado em 1994 por Elkington, o termo "triple bottom line"significa que todas as entidades, governamentais ou não, no desempenho de suas atividades, necessitam observar um viés não meramente social ou econômico, mas também ambiental para um desenvolvimento tido por sustentável. A definição de Elkington, direcionada para o universo corporativo, baseava-se nos "três P's", que são: profits (lucro), people (pessoas) e planet (planeta). (MARTINS; SILVA, 2018, p. 12).

Ademais, uma análise do desenvolvimento sustentável exige, dentro do Estado de Direito Ambiental, a observância aos Princípios Constitucionais da Democracia, legitimados na atuação dos Poderes Executivo, Legislativo e Judiciário, tendo em vista o respeito às normas jurídicas e a liberdade dos cidadãos em participar da definição de estratégias para o desenvolvimento econômico e social. (SENGUPTA, 2002).

Com isso, o Desenvolvimento Sustentável preconiza a possibilidade de se atingir o desenvolvimento social, econômico e cultural, a partir do uso razoável dos recursos naturais. (CAVALCANTE, 2017, p. 124).

Assim, o desenvolvimento deve ser sustentado no pilar do Estado de Direito Ambiental, ou seja, pelos princípios constitucionais de respeito ao meio ambiente e pelo arcabouço legislativo dele decorrente (CAVALCANTE, 2017, p. 124). Esta nova concepção não deve ser interpretada como "nunca levar em consideração os interesses humanos", mas deve-se compreender que os interesses humanos não definem e nem comandam todos dos "horizontes de valores", reconhecendo que há valores naturais, que os homens devem respeitar (PIERRI; FOLADORI, 2001, p. 81128). Assim, este Estado pressupõe não só direitos, mas também deveres, tanto do Estado como da sociedade civil. (RUSCHEL, 2007, p. 56).

Neste sentido, afirma-se que todo o ciclo produtivo e financeiro deve-se pautar pela obediência aos princípios constitucionais. $O$ desenvolvimento requer 
atenção à ordem jurídica, mas não apenas a parte que convém ao crescimento do produto, mas sim às normas ambientais, construídas e legitimadas democraticamente, que visem à preservação da natureza como elemento essencial da qualidade de vida dos cidadãos. (CAVALCANTE, 2017, p. 124).

Além disso, o desenvolvimento exige o respeito à Constituição, às normas infraconstitucionais e internacionais, especialmente de matriz ambiental. Com isso, deve ser reconhecida a centralidade da liberdade individual e da força das influências sociais sobre o grau e o alcance da liberdade individual. Pois, para combater os problemas hodiernas, deve haver um comprometimento social. (SEN, 2000, p. 10).

Outrossim, é necessário que o Estado e as demais instituições de planejamento, controle interno e externo, se fortaleçam, no sentido de capacitar a equipe, melhorar a metodologia e as técnicas de trabalho, planejamento, fiscalização, aplicação de sanções e orientação aos cidadãos, administrados e jurisdicionados, pessoas físicas e jurídicas, para permitir procedimentos administrativos e processos judiciais eficazes, impessoais e transparentes, em respeito aos princípios da eficiência, prevenção, precaução, poluidor-pagador e proibição de retrocesso ou não regressão. (PRIEUR, 2012).

Dessa forma, deve-se haver uma concepção de que, com o Desenvolvimento Sustentável, e dentro do Estado de Direito Ambiental, o respeito ao meio ambiente não seja tratado como faculdade, mas como dever jurídico.

Ademais, frisa-se que entender o desenvolvimento como transformação de mentalidade significa que todos os agentes assumirão responsabilidades, sendo necessário o empoderamento da população, através da participação ativa e eficaz. (CAVALCANTE, 2017, p. 131).

Diante do exposto, ao analisar o Desenvolvimento Sustentável, nota-se que este possui como pilar o Estado de Direito Ambiental, e que, com isto, exige-se o respeito às normas ambientais. Portanto, o Desenvolvimento Sustentável exige o respeito ao Estado de Direito Ambiental.

Assim, deve-se haver a aplicação e efetivação do Desenvolvimento Sustentável, que tem como pilar o Estado de Direito Ambiental, como forma de amenizar as consequências oriundas das atividades de mineração. 
Por fim, ao ver que a legislação na Colômbia não é cumprida em sua totalidade, mostra-se essencial um outro tipo de orientação, pautada pelo Desenvolvimento Sustentável, como forma de proteger o meio ambiente e assegurar à população todos os direitos e garantias inerentes a ele.

\section{CONCLUSÃO}

A mineração é uma atividade presente em muitos países da América Latina. Na Colômbia, o exercício da mineração faz parte de sua economia e da vida da sua população. Contudo, esta atividade extrativista acarreta problemáticas socioambientais.

Assim, para que seja possível uma análise mais precisa desta problemática, delimitou-se a classificação das consequências das atividades de mineração como sendo "desastres ambientais". Além disso, vislumbrou-se que o Direito Ambiental está umbilicalmente ligado ao Direito dos Desastres.

Com a análise da legislação da Colômbia, viu-se que este país possui uma legislação que regula as atividades de mineração. Assim, investigou-se a Resolução 40391 de 2016, que adota a Política Nacional de Mineração, e viu-se que esta norma formaliza a mineração como forma de atenuar as problemáticas ocasionadas pela mineração. Contudo, destaca-se que esta norma não é cumprida e efetivada em sua totalidade, acarretando, assim, entraves ambientais e sociais.

Neste sentido, analisou-se o Departamento de Antioquia (Bajo Cauca), Departamento De Cauca, Departamento del Chocó, Departamento de Córdoba, Departamento Bolívar e o Departamento de Caldas. Com isso, foi possível visualizar que o meio ambiente e população dessas regiões são negativamente afetados pelas atividades de mineração.

Dessa forma, nota-se que a Colômbia, apesar de apresentar uma legislação que protege o meio ambiente, não é respeitada em sua totalidade. Uma vez que foi possível notar que as regiões supramencionadas sofrem impactos ocasionados pela mineração ilegal e informal. 
Diante disso, apresenta-se o Desenvolvimento Sustentável, que possui como pilar o Estado de Direito Ambiental, com ferramentas que atenuam as consequências negativas decorrentes da mineração na Colômbia.

Assim, para fortalecer o já disposto em lei, mostra-se necessária a aplicação e efetivação do Desenvolvimento Sustentável, que tem como pilar o Estado de Direito Ambiental.

Com isso, diante da ineficaz legislação, deve-se haver uma orientação pautada pelo Desenvolvimento Sustentável. Somente assim ter-se-á um meio ambiente saudável e equilibrado capaz de suprir as necessidades das presentes e futuras gerações.

\section{REFERÊNCIAS}

ANLA. Autoridad Nacional de Licencias Ambientales - ANLA. Bogotá: ANLA, 2015. Disponível em: http://www.anla.gov.co/contenido/contenido.aspx?catID =1373\&conID=8044. Acesso em: 22 set. 20220.

ARAUJO, E. R.; FERNANDES, F. R. C. Mineração no Brasil: crescimento econômico e conflitos ambientais. In: GUIMARÃES, P. E.; CEBADA, J. D. P. Conflitos ambientais na indústria mineira e metalúrgica. Rio de Janeiro: CETEM/CICP, 2016. p. 6588. Disponível em: http://mineralis.cetem.gov.br/handle/cetem/1909. Acesso em: 7 jun. 2020.

CANOTILHO, José Joaquim Gomes; LEITE, José Rubens Morato (org.). Direito constitucional ambiental brasileiro. 2. ed. São Paulo: Saraiva, 2008.

CARVALHO, Délton Winter de. Desastres ambientais e sua regulação jurídica: deveres de prevenção, resposta e compensação ambiental. 2. ed. rev., atual. e ampl. São Paulo: Thomson Reuters Brasil, 2020.

CAVALCANTE, Priscila da Mata. Desenvolvimento sustentável no estado de direito ambiental. RACEF - Revista de Administração, Contabilidade e Economia da Fundace, [S. I.], v. 7, n. 3, p. 122-136, 2017. Disponível em: file://C:/Users/ariel/Downloads/Desenvolvimento\%20sustent\%C3\%A1vel\%20e\%20 Estado\%20de\%20Direito\%20Ambiental\%20-\%20Priscila\%20Cavalcante.pdf. Acesso em: 26 jun. 2020.

COLÔMBIA. Resolución numero 40391 de 20 de abril de 2016. Por la cual se adopta la Política Minera Nacional. Bogotá: Ministerio de Minas Y Energia, 2016. p. 164. Disponível em: 
https://redjusticiaambientalcolombia.files.wordpress.com/2016/04/politica-nacionalminera-resolucion-40391-2016.pdf. Acesso em: 26 jul. 2020.

COSTA, Maria Alice Nunes. Sinergia e capital social na construção de políticas sociais: a favela da Mangueira no Rio de Janeiro. Revista de Sociologia e Política, Curitiba, n. 21, p. 147-163, nov. 2003. Disponível em: https://www.scielo.br/scielo.php?pid=S0104$44782003000200010 \&$ script=sci_arttext. Acesso em: 15 maio 2020.

DAVIS, G. A. The mineral sector, sectoral analysis, and economic development. Resources Policy, [S. I.], v. 24, n. 4, p. 217-228, 1998. Disponível em: https://www.sciencedirect.com/science/article/abs/pii/S0301420798000348?via\%3Di hub. Acesso em: 27 jul. 2020.

FARBER, Daniel. Navigating the intersection of environmental law and disaster law. BYU Law Review, [S. I.], v. 2011, n. 6, p. 1783-1820, 2011. Disponível em: https://digitalcommons.law.byu.edu/lawreview/vol2011/iss6/1/. Acesso em: 23 jul. 2020.

FREITAS, Juarez. Sustentabilidade: direito ao futuro. 3. ed. Belo Horizonte: Fórum, 2011.

GÓMEZ, Jorge Armando Otálora et al. A mineração descontrolada: uma abordagem de violação dos direitos humano. Bogotá: Defensoría Del Pueblo, 2015. Disponível em:

https://www.defensoria.gov.co/public/pdf/InformedeMinerIa2016.pdf. Acesso em: 26 jul. 2020.

LEITE, José Rubens Morato; BELCHIOR, Germana Parente Neiva. O Estado de direito ambiental e a particularidade de uma hermenêutica jurídica. Seqüência: Estudos Jurídicos e Políticos, [S. I.], v. 31, n. 60, p. 291-318, 2010. Disponível em: https://periodicos.ufsc.br/index.php/sequencia/article/view/16503. Acesso em: 27 jul. 2020.

MARTINS, Natalia Camba; SILVA, Alice Rocha da. As contribuições das teorias liberais à implantação da decisão do caso dos pneus reformados. In: DIZ, Jamile Bergamaschine Mata; SERRANO, Ruben; TOMAZ, Carlos Alberto Simões de (coord.). Direito, estado e sustentabilidade. Belo Horizonte: Arraes Editores, 2018. p. 116.

PIERRI, Naína; FOLADORI, Guillermo. Sustentabilidad? desacuerdos sobre el desarrollo sustentable. Montevideo: Trabajo y capital, 2001.

PRIEUR, M. O princípio da proibição do retrocesso ambiental. In: BRASIL. Princípio da Proibição do Retrocesso Ambiental. Brasília, DF: Senado Federal: Comissão de Meio Ambiente: Defesa do Consumidor e Fiscalização e Controle, 2012, p. 11-54. Disponível em: http://www.mp.ma.gov.br/arquivos/CAUMA/ Proibicao\%20de\%20Retrocesso.pdf. Acesso em: 27 jul. 2020. 
QUIJANO, P.; PARDO, M. Elementos de diagnósticos para una caracterización de la minería en Colombia. Bogotá: [s. n.], 2010.

RADETZKI, M. Regional development benefits of mineral projects. Resources Policy, [S. I.], v. 8, n. 3, p. 193-200, 1982. Disponível em: https://www.sciencedirect.com/science/article/abs/pii/0301420792900369. Acesso em: 27 jul. 2020.

RUSCHEL, Caroline Vieira. Parceria ambiental: o dever fundamental de proteção ambiental como pressuposto para concretização do estado de direito ambiental. 2007. Dissertação (Mestrado em Direito) - Centro de Ciências Jurídicas, Universidade Federal de Santa Catarina, Santa Catarina, 2007. Disponível em: https://repositorio.ufsc.br/bitstream/handle/123456789/103032/241393.pdf?sequenc e=1\&isAllowed=y. Acesso em: 27 jul. 2020.

SCOTTO, Gabriela. Estados nacionais, conflitos ambientais e mineração na América Latina. In: SEMINÁRIO DE PESQUISA DO INSTITUTO DE CIÊNCIAS DA SOCIEDADE E DESENVOLVIMENTO REGIONAL DA UNIVERSIDADE FEDERAL FLUMINENSE, 4., 2011, Campos dos Goytacazes. Anais [...]. Campos dos Goytacazes: UFF, 2011.

SEN, A. Desenvolvimento como liberdade. Tradução: Laura Teixeira Motta. São Paulo: Companhia das Letras, 2000.

SENGUPTA, A. O direito ao desenvolvimento como um direito humano. Social Democracia Brasileira, [S. I.], n. 68, 2002. Disponível em: http://www.itv.org.br/site/publicacoes/igualdade/direito_desenvolvimento.pdf. Acesso em: 28 set. 2007.

SIMCO. Catastro Minero Nacional Y Registro Minero Nacional. Sistema de Información Minero Colombiano (SIMCO), Bogotá, 2014.

SUGARMAN, Stephen D. Roles of government in computing disaster victims. Issues in Legal Scholarship, [S. I.], v. 6, n. 3, p. 1-33, 2007. Disponível em: https://www.degruyter.com/view/journals/ils/6/3/article-ils.2007.6.3.1093.xml.xml. Acesso em: 27 jul. 2020.

VILLALOBOS, Camilla. Resumen de la nueva política minera en Colombia: Resolución 40391 de 2016. Red por la Justicia Ambiental en Colombia, [S. I.], 2016. Disponível em: https://justiciaambientalcolombia.org/resumen-politica-minera/. Acesso em: 27 jul. 2020. 